\title{
Rheological control of the coffee stain effect for inkjet printing of ceramics
}

\author{
A. Friederich, J. R. Binder, W. Bauer
}

\section{Introduction}

Coffee staining is a general problem of inkjet printing ceramic suspensions. It is caused by a flow of liquid from the centre to the edge of a drying drop and leads to a non-uniform deposition of particles. Conventional thick-film preparation methods such as screen printing do not show coffee staining due to the high viscosity of the printing medium.

The approaches to prevent coffee staining that are reported in the literature make use of various physical phenomena such as the Marangoni flow or electro-wetting to obtain homogeneous films.

We present a new approach, which follows a simple consideration: Coffee staining can be suppressed by a sufficiently fast increase of viscosity after deposition. However, the ink viscosity during printing is usually restricted to very low values due to the small diameter of the printhead nozzles. Hence, inks with tailored viscosity need to be developed.

\section{Ink preparation and ink properties}

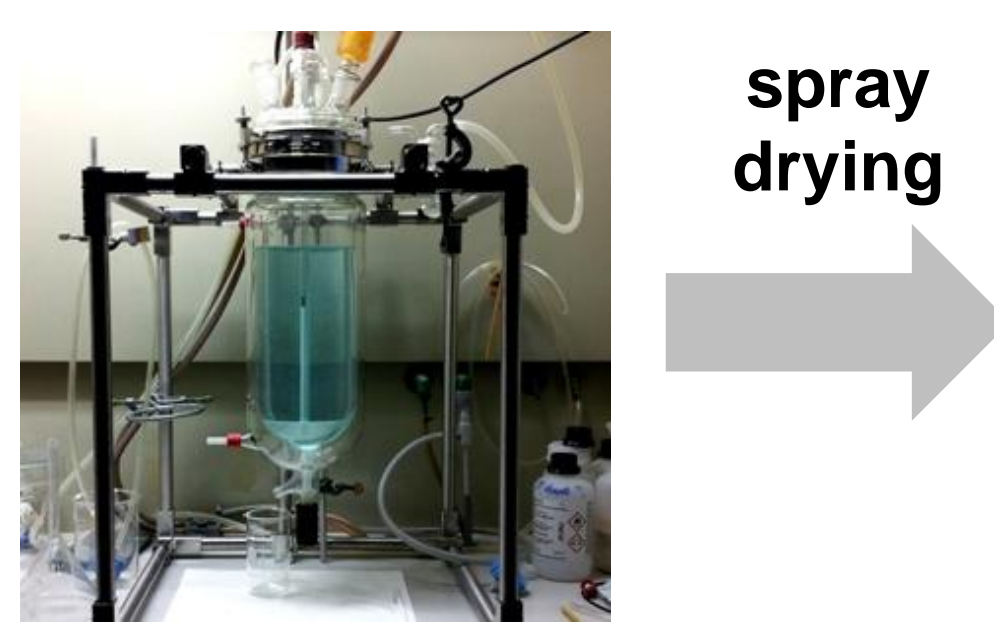

$\begin{array}{ll}\text { Material: } & \mathrm{Ba}_{0.6} \mathrm{Sr}_{0.4} \mathrm{TiO}_{3} \\ \text { Solvent: } & \text { butyl diglycol }\end{array}$

Ink properties:
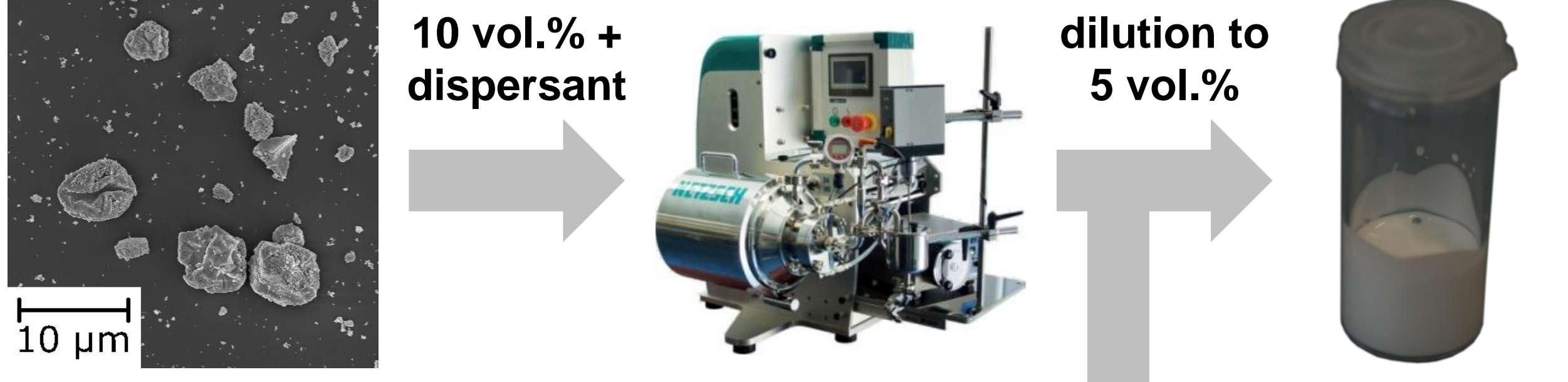

$\rightarrow$ Long time stable

$\rightarrow$ Particle size:

$\rightarrow$ Surface tensio

$\rightarrow$ Viscosity:

+ 0-1.25 vol.\% ethyl cellulose (EC) + 0-50 vol.\% isopropy alcohol (IPA)

printing

$\rightarrow 0.09<\mathrm{O} h<0.71 \rightarrow$ all inks well printable

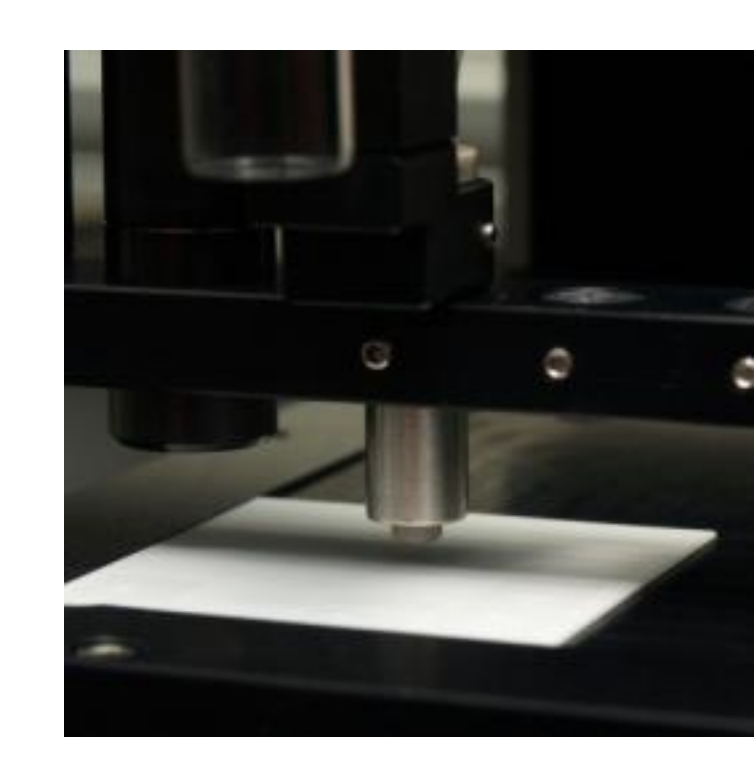

\section{Characterisation of dried structures}

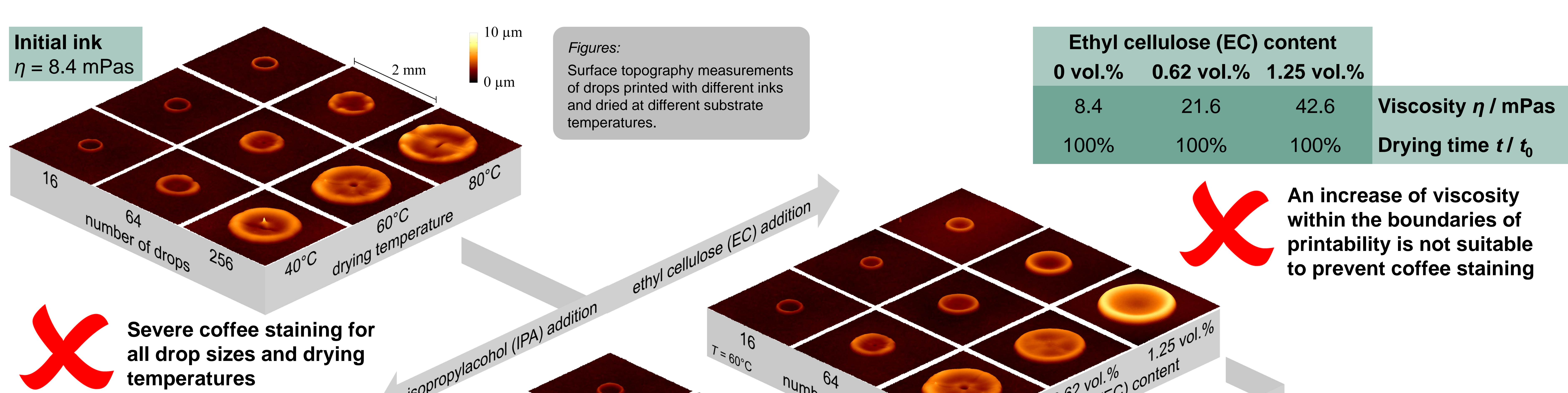

Isopropyl alcohol (IPA) content

0 vol. $\% \quad 25$ vol. $\% \quad 50$ vol. $\%$

$\begin{array}{cccl}8.4 & 5.9 & 4.6 & \text { Viscosity } \boldsymbol{\eta} / \mathrm{mPas} \\ 100 \% & 80 \% & 55 \% & \text { Drying time } \boldsymbol{t} / \boldsymbol{t}_{0}\end{array}$

A decrease of drying time is not suitable to prevent coffee staining, if the viscosity is also lowered.

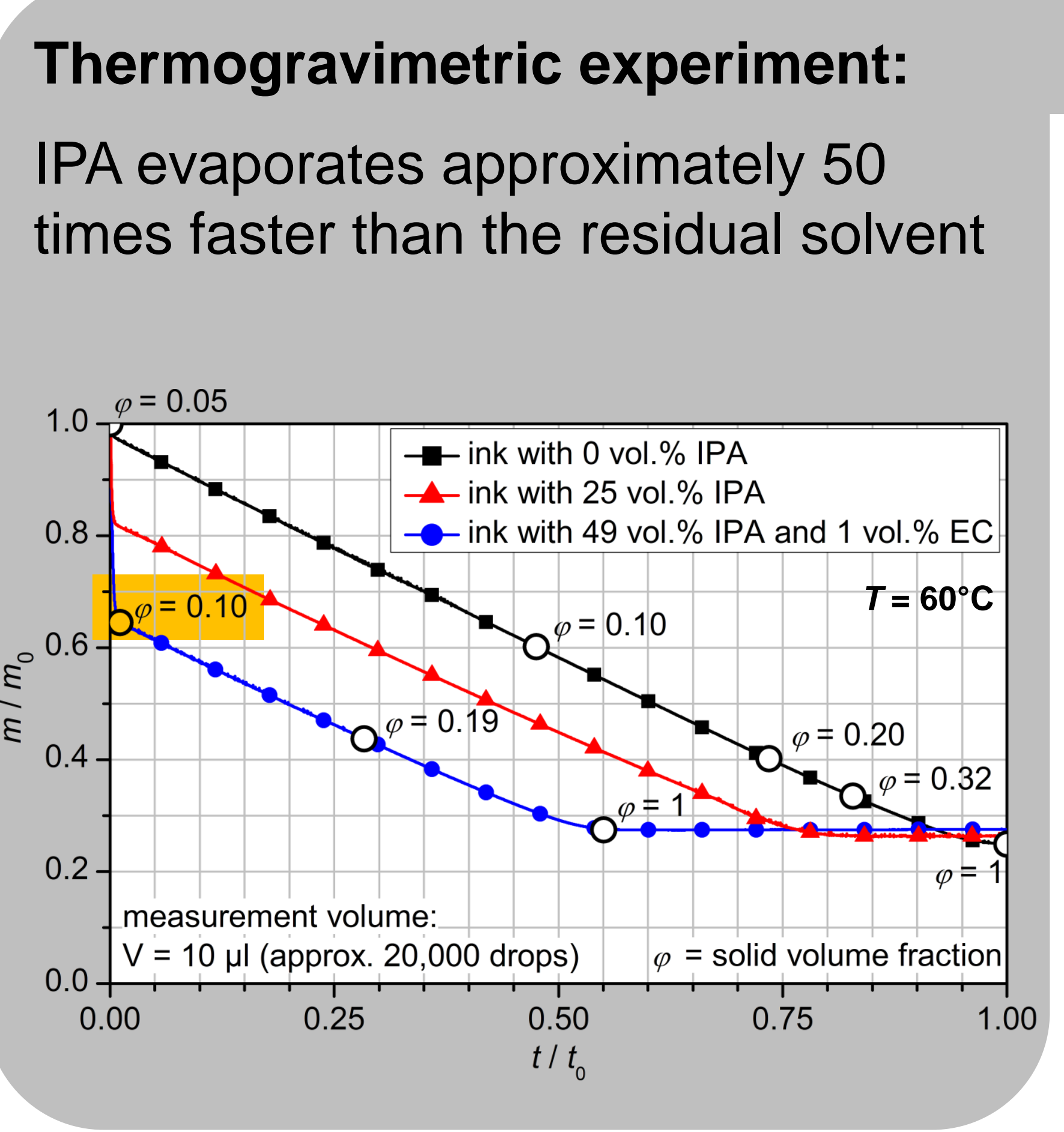

Rheology measurements:

The viscosity of the ink with $\mathrm{EC}$ and IPA rises about 1 order of magnitude in a very short time span

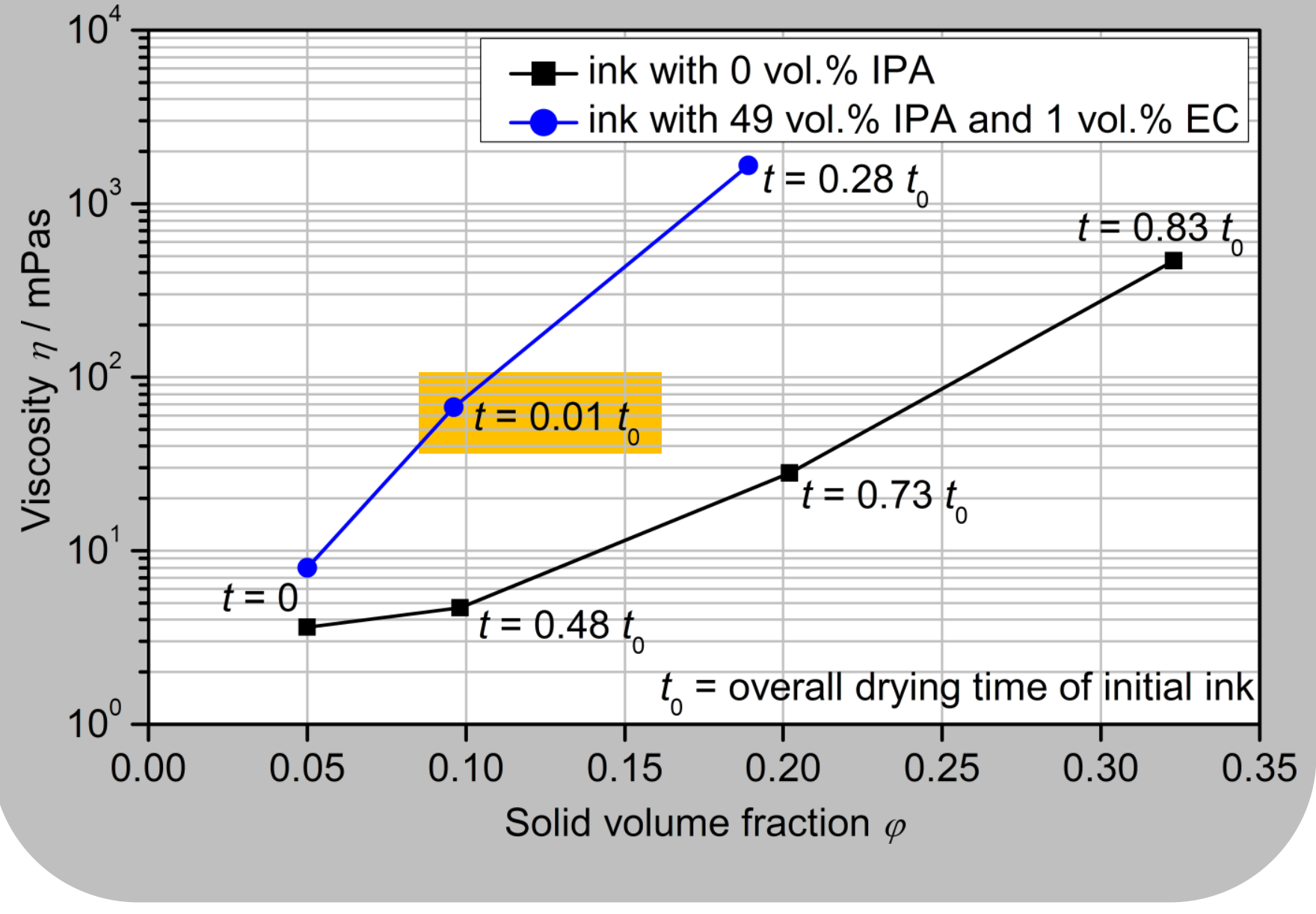

